The total number of laboratory tests in that year was about nine million-about 5.7 million in health centre main laboratories; about 2.3 million in side-laboratories (in other words, these were done mainly by public health nurses); and the rest either in hospital or government laboratories outside the health centres. At the same time about $560000 x$-ray examinations were done, only 64000 or so of these being done outside the health centres. ${ }^{9}$

\section{Twin benefits}

Both the general practitioner and patient benefit from the former's ability to continue his patient's treatment in hospitalfor example, when the practitioner has hospital beds at his disposal and under his control without being subordinate to a specialist in the hospital. ${ }^{10}$ In the Finnish system in 1973 about 5800 beds in health centre wards were under the control of the practitioners working there-a ratio of 1.25 per 1000 population. This represents about $20 \%$ of all general hospital beds and over $10 \%$ of total hospital beds. The cost of a bed in a health centre hospital then was $60 \%$ cheaper than that in a central hospital.

Hence there are interesting differences in the present Finnish system compared with the British system-an aspect dealt with more thoroughly in other articles. ${ }^{11}{ }^{12}$ Nevertheless, the concepts first mooted over 50 years ago in Britain are now being applied both there and in other countries such as Finland, modified in the latter by national and local priorities and circumstances and also by different medical and health care delivery systems. Given the facts of recent medical history in Britain it was obviously necessary to change the status of the British GP, who over two decades had become isolated before the introduction of the charter-an opinion even confirmed bv an official publication. ${ }^{13}$

\section{References}

${ }^{1}$ Brotherston, J, in Medical History and Medical Care, a Symposium of Perspectives, ed G McLachlan and T McKeown. London, Oxford University Press, 1971.

${ }^{2}$ Ministry of Health, The Future Provision of Medical and Allied Services. London, HMSO, 1920. (Dawson Report)

${ }^{3}$ Finland, Community Health Care Act, Helsinki, 1972.

4 Finnish Medical Association Statistics, Helsinki, 1975.

${ }^{5}$ Department of Health and Social Security, Digest of Health Statistics for 1971. London, HMSO, 1971.

${ }^{6}$ Finland, National Board of Health, Health Centres Statistics of 1973, Helsinki, 1974.

${ }^{7}$ Mcdonald, A, and McLean, I G, Study of the Work of general Practitioners, Practitioner, 1971, 207, 680 .

${ }^{8}$ Scottish Home and Health Department, June 1975, personal communication.

${ }^{9}$ Kasari, K, Community Health Care and its Costs in 1974, The Finnish Communities, 1975, 19, 1128.

10 Lancet, 1972, 2, 411

11 Kekki, Pertti, British Medical fournal, 1975, 4, 273.

12 Kekki, Pertti, and Garraway, Michael, "Contrasts and Comparisons of General Practice between Finland and Scotland," 1975. Unpublished.

13 Scottish Home and Health Department, Doctors in an Integrated Health Service. Edinburgh, HMSO, 1971.

\title{
Angiographic appearance of carotid bifurcation in patients with completed stroke, transient ischaemic attacks, and cerebral tumour
}

\author{
M J G HARRISON, JOHN MARSHALL
}

British Medical fournal, 1976, 1, 205-207

\section{Summary}

The angiographic appearance of the carotid bifurcation was compared in groups of patients aged 50-59 suffering from transient ischaemic attacks (40 cases), cerebral infarction with completed stroke (44 cases), and cerebral hemisphere tumour (66 cases). Carotid occlusion was found in $14 \%$ of those with infarcts and $5 \%$ of those with transient ischaemic attacks. Carotid stenosis was found in $40 \%$ of those with ischaemic attacks and $14 \%$ of those with infarcts. Minor irregularity of the carotid arterial wall was equally common in all three groups.

Department of Neurological Studies, Middlesex Hospital Medical School, London W1N 8AA

M J G HARRISON, DM, MRCP, physician

The National Hospital, Queen Square, London WC1N 3BG

JOHN MARSHALL, MD, FRCP, professor of clinical neurology

\section{Introduction}

The prevalence of abnormalities of the internal carotid artery in the neck in patients with cerebrovascular disease has been frequently studied. While it is accepted that embolism from ulcerated carotid atheroma may cause transient ischaemic attacks, ${ }^{1}$ studies of patients who have suffered a major cerebral infarction have confirmed only the role of carotid occlusion. ${ }^{2}$ There have been few studies, however, in which the angiographic appearances of major neck vessels have been compared in patients with transient ischaemic attacks, cerebral infarcts, and a control population. We thought that such a comparison would be of value. Patients undergoing carotid angiography for hemisphere tumours were chosen as a control group.

\section{Methods}

Patients of either sex in the age group 50-59 were studied.

Transient ischaemic attacks-Forty patients ( 7 women, 33 men) aged 50-59 had angiography by low common carotid artery puncture during investigation by one of us (JM) for more than one transient ischaemic attack in the carotid territory. These patients were from the larger group discussed elsewhere. ${ }^{3}$ 
Cerebral infarcts-We investigated 44 patients ( 17 women, 27 men) aged 50-59 who had sustained a completed stroke in one carotid territory by common carotid puncture angiography. They were among those studied elsewhere. ${ }^{4}$

Tumours-We selected patients with a supratentorial tumour aged from 50 to 59 from a consecutive series of patients admitted and investigated at the National Hospital, Queen Square. We chose 66 in whom a low common carotid puncture angiogram had been carried out with views taken of the bifurcation ( 26 women, 40 men).

Angiograms-The neck films were reviewed by one of us (MJGH) without access to the clinical data. The bifurcation was traced and any narrowing measured. ${ }^{5}$ Many patients had been studied over 10 years ago, before the present policy of always obtaining biplanar views of the bifurcation. Two or more views were available in $49 \%$ of the tumour cases, $32 \%$ of the infarct cases, and $43 \%$ of the transient ischaemic attack group. The vessels were classified as normal or as showing minimal irregularity, stenosis, or occlusion. Stenosis was classified as $25 \%$ or less, $75^{\circ}$ or more, or of intermediate degree. The findings in the patients with crebrovascular disease were compared with those in the tumour "control" group using $\chi^{2}$ tests of significance. Since a previous study ${ }^{6}$ considered only men, the findings of the present study were also separately calculated for men and women.

\section{Results}

The carotid bifurcation appeared normal in $86 \%$ of the patients with tumours. Irregularity without appreciable narrowing was seen in $10^{\circ}$ \% One patient had mild encroachment on the lumen (15 $\%$ narrowing) and another had $40 \%$ stenosis. Among the patients with a recent cerebral infarct a normal appearance of the carotid artery in the neck was less common than in the tumour group $(57 \% \mathrm{P}<0.001)$. Minor irregularities were slightly more common but the difference was not significant. Stenosis was more frequently encountered $\left(14^{\circ}, 0\right.$ compared with $3^{\circ}$ o $\mathrm{P}<0.01$ ). Two patients had a tight stenosis (over $75^{\circ}$ o narrowing). The most striking feature was the prevalence of carotid occlusion $(14 \%)$, not seen in the tumour group $(P<0.01)$.

In the transient ischaemic attack group normal appearances in the cervical segment of the carotid artery were again less common than in the tumour cases $\left(45^{\circ} ; \mathrm{P}<0.001\right)$. Minor irregularity was no more common $(10 \%)$ but stenosis much more so $\left(40^{\circ} ; \mathrm{P}<0.001\right)$. Thirteen per cent had a tight stenosis of over $75^{\%}$ and $18^{\circ}$, had a narrowing of moderate degree $(25-75 \%)$. Two patients had an occluded carotid artery.

Thus abnormalities of the carotid artery in the neck attributable to atheroma or thrombosis were strikingly more prevalent in patients with a clinical diagnosis of cerebrovascular disease (table I). Carotid occlusion did not occur in the tumour group and was most commonly encountered in the group of patients suffering from a completed stroke.

TABLE I-Prevalence of angiographic abnormalities

\begin{tabular}{|c|c|c|c|}
\hline $\begin{array}{l}\text { Appearance of } \\
\text { carotid bifurcation }\end{array}$ & Tumour & Infarct & $\begin{array}{c}\text { Transient } \\
\text { ischaemic } \\
\text { attack }\end{array}$ \\
\hline $\begin{array}{l}\text { No of patients } \\
\text { Normal } \\
\text { Irregular wall } \\
\text { Stenosis all grades } \\
\text { Occlusion }\end{array}$ & 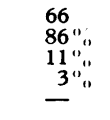 & 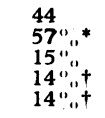 & $\begin{array}{l}40 \\
450 " \\
100 " \\
400 " \\
50 "\end{array}$ \\
\hline
\end{tabular}

Significance of difference from findings in tumour group $\chi^{2}$ test ${ }^{*} \mathrm{P}<0.001,+\mathrm{P}<0.01$.

Minor atheromatous irregularity did not appear to be correlated with the presence or absence of symptomatology attributed to vascular disease. Atheromatous stenosis was more common in patients with infarcts than in those with tumours, but was most obvious in the groups uffering from transient ischaemic attacks. The same picture was apparent when only men were considered (table II).

TABLE II-Prevalence of vessel wall changes in men aged 50-59

\begin{tabular}{l|c|c|c}
\hline & $\begin{array}{c}\text { Tumour } \\
(40)\end{array}$ & $\begin{array}{c}\text { Infarct } \\
(27)\end{array}$ & $\begin{array}{c}\text { Transient } \\
\text { ischaemic } \\
\text { attack (33) }\end{array}$ \\
\hline $\begin{array}{lll}\text { Stenosis all grades } \\
\text { Irregularity in wall }\end{array}$ & $\begin{array}{c}3^{\circ} \% \\
29^{\circ} \%\end{array}$ & $\mathbf{1 4} \%$ & $\mathbf{4 7} \%$ \\
\hline
\end{tabular}

\section{Discussion}

Poser et $a l^{6}$ reported a comparison of arch angiography in patients aged 40 to 65 with symptoms due to cerebrovascular disease and in a group of healthy men. ${ }^{7}$ The age distribution of the two groups was very different but sufficient numbers were available for comparison in the 40-49 bracket (men only). In this subgroup Poser $e t a l^{6}$ found a slightly higher prevalence of intra-arterial abnormalities $\left(56^{\circ}{ }_{0}\right.$ compared with $\left.42^{\circ}{ }_{0}\right)$ in the patients. They found, however, that carotid occlusion had been shown 21 times in the 250 cerebrovascular patients (all ages), but never in the 93 healthy, rather younger, patients. A distinction was not made between patients with transient ischaemic attacks and those with completed strokes.

Drake and Drake ${ }^{*}$ compared the distribution of arterial stenoses on arch angiography with the arterial territory corresponding to symptoms in 89 patients. The accuracy of localisation of symptoms is poor: but Drake and Drake showed a correspondence of extracranial stenosis to symptoms, particularly in the carotid circulation. We extended the observations of these earlier reports by comparing angiograms with those in an agematched control population and by distinguishing patients with transient ischaemic attacks and major cerebral infarcts.

That transient ischaemic attacks are often due to microembolism from a stenosed segment of the cervical carotid artery has been established by clinical observation of retinal emboli, 9 operative findings, ${ }^{1}$ and the success of endarterectomy in preventing recurrences. ${ }^{10}$ We have shown that stenotic disease of the cervical carotid artery is significantly more prevalent in patients suffering from transient ischaemic attacks than in controls (tumour cases). Although it is believed that emboli may form on shallow ulcers on the carotid wall in the absence of stenosis, probably emboli are more likely in the presence of appreciable narrowing of the vessel. Turbulent flow caused by the narrowing may make the formation of a platelet-fibrin mass more likely.

Mitchell and Schwartz," in a careful necropsy study, found that carotid and vertebral stenosis was not, however, clearly related to the occurrence of a major stroke. The role of occlusion of the neck vessels in producing a major infarct was clear. Carotid occlusion is found in some $20 \%$ of patients suffering from a major hemisphere infarct whether studied angiographically ${ }^{11}$ or at necropsy. ${ }^{2}$ Carotid occlusion is rare in angiograms carried out for other purposes. ${ }^{12}$ We confirm the important association of carotid occlusion with a major infarct when compared with a control group. Our data also suggest that carotid stenosis, but not minor degrees of irregularity, is more prevalent in patients with infarcts.

Many cerebral infarcts are thought to be due to cardiac emboli and in some series this mechanism is thought to be responsible for $40-50 \%$ of cases. ${ }^{13} 14$ Since ischaemic heart disease with myocardial infarction is one of the sources of cardiac emboli, a chance association of cerebral infarction and any evidence of generalised atheroma might occur.: Some examples of carotid occlusion are due to cardiac emboli, though others are thought to be due to thrombosis on local vessel wall disease. ${ }^{15}$

With these provisos it appears reasonable on the present data to attach pathological significance to carotid stenosis in transient ischaemic attacks and to carotid occlusion, and possibly also to carotid stenosis, in completed strokes due to cerebral infarction. Minor irregularities of the carotid wall on angiograms have not been shown to be significantly more common in patients with cerebrovascular disease than in a control group. Observation at endarterectomy suggests, however, that minor angiographic abnormality may be seen with shallow ulceration with a mural thrombus. We hope that improved angiographic technique with magnification will make it possible to detect those cases in which minor irregularities are in fact of pathological importance.

\section{References}

${ }^{1}$ Gunning, A J, et al, Quarterly fournal of Medicine, 1964, 33, 155. 
2 Mitchell, J R A, and Schwartz, C J, Arterial Disease. Oxford, Blackwell, 1965.

Harrison, M J G, and Marshall, J, British Medical fournal, 1975, 1, 616.

1 Harrison, M J G, and Marshall, J, Fournal of the Neurological Sciences, $1975,24,243$.

'Alter, M, et al, Neurology, 1972, 22, 590.

'Poser, C M, et al, Acta Neurologica Scandinavica, 1964, 40, 321.

' Faris, A A, et al, Neurology, 1963, 13, 386.

'Drake, W E, and Drake, M A L, American fournal of Medicine, 1968, $45,253$.
${ }^{9}$ Russell, R W R, Lancet, 1961, 2, 1422.

1" Fields, W S, et al, fournal of the American Medical Association, 1970, 211, 1993.

11 Bull, J W D, Marshall, J, and Shaw, D A, Lancet, 1960, 1, 562.

12 Feiring, E H, Neurology, 1954, 4, 405.

${ }^{13}$ Blackwood, W, et al, Brain, 1969, 92, 897.

14 Torvik, A, and Jorgensen, L, fournal of the Neurological Sciences, 1964, $1,24$.

15 Castaigne, P, et al, Brain, 1970, 93, 231.

\title{
Clinicopathological Conference
}

\section{A case of septicaemia}

\author{
DEMONSTRATED AT THE ROYAL COLLEGE OF PHYSICIANS OF LONDON
}

British Medical fournal, 1976, 1, 207-212

The eleventh of the quarterly series of clinicopathological conferences was held at the Royal College of Physicians of London on 24 April 1975. Professor G P McNicol(1) presented the case, with Dr S H Taylor(2), Dr M F Dixon(3), and Dr R Freeman (5).

\section{Clinical summary}

HISTORY

A 45-year-old woman was admitted to hospital on 31 January 1974 confused and disorientated. She had apparently been unwell for three days, with rigors, loose stools, and an episode of vomiting. She had a mitral valvotomy for mitral stenosis in 1962; paranoid schizophrenia since 1962; temporal lobe epilepsy since 1949; and psoriasis since 1948. There was no history of rheumatic fever. Treatment immediately before admission was unknown but in recent months she had been on digoxin, chlorpromazide, pimozide, phenytoin, amitriptyline, nitrazepam, and Conovid E (oral contraceptive: mestranol and norethynodrel).

\section{EXAMINATION ON ADMISSION}

Confused and disorientated. Temperature $38.5 \mathrm{C}$. Edentulous. Extensive psoriasis with haemorrhagic areas and purpura. Fingertips cold and cyanosed. Peripheral pulses all palpable. Pulse rate $150 / \mathrm{min}$, irregular. Blood pressure $130 / 80 \mathrm{~mm} \mathrm{Hg}$. Heart enlarged clinically, particularly the left ventricle, but no clinical evidence of heart failure. Pansystolic murmur at apex. Lungs clear. Appreciable neck rigidity and Kernig's sign positive. No papilloedema and no focal neurological signs. No abnormal findings in abdomen. No splinter haemorrhages, no Osler's nodes, no haematuria.

The results of the initial investigations included: haemoglobin $12.4 \mathrm{~g} / \mathrm{dl}$; white blood count $17.5 \times 10^{9} / 1$; polymorph neutrophil leucocytosis; platelet count $6 \times 10^{9} / 1$; electrocardiogram showed rapid atrial fibrillation; $x$-ray film of chest showed generalised cardiac enlargement; blood urea $10 \mathrm{mmol} / 1(60 \mathrm{mg} / 100 \mathrm{ml})$; serum sodium $135 \mathrm{mmol} / 1(135 \mathrm{mEq} / \mathrm{l})$; serum potassium $3.2 \mathrm{mmol} / 1(3.2 \mathrm{mEq} / \mathrm{l})$; $\mathrm{CO}_{2} 20 \mathrm{mmol} / \mathrm{l}(20 \mathrm{mEq} / \mathrm{l})$; blood culture gave a growth of coagulasepositive staphylococcus.

Two platelet infusions of eight units each were given and lumbar puncture was performed. This showed no evidence of meningitis and the cerebrospinal fluid (CSF) culture was sterile.

\section{PROGRESS AFTER ADMISSION}

For three days the patient's clinical condition remained essentially unchanged apart from the development of gangrene of the fingertips.
Her general condition then gradually improved: her temperature fell to normal and her platelet count rose by 5 February to $94 \times 10^{9} / 1$. Skin biopsy was performed on that day; the results will be presented. Further general improvement then gradually continued until she developed diarrhoea on 11 and 12 February. Blood urea on 12 February was $12.3 \mathrm{mmol} / 1(74 \mathrm{mg} / 100 \mathrm{ml})$. Gangrene of the fingertips was by this time fully established and the patient's condition began to deteriorate. On 13 February she had an episode of pulmonary oedema which appeared related to a brief cardiac dysrhythmia. The next day the platelet count was $77 \times 10^{9} / 1$; blood urea had risen to $30 \mathrm{mmol} / 1$ $(156 \mathrm{mg} / 100 \mathrm{ml})$. On 15 February there were two episodes of ventricular fibrillation, the second being fatal. The course is outlined in fig 1 .
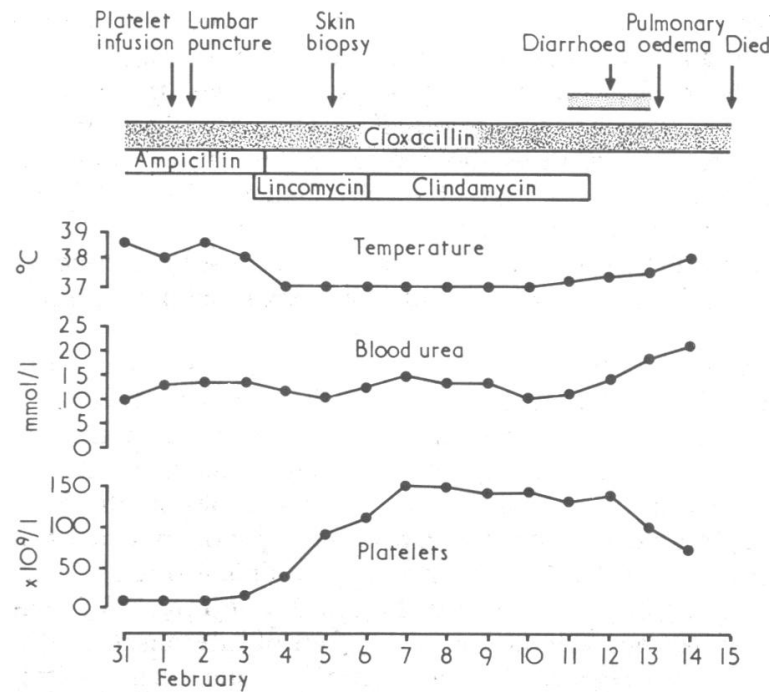

FIG 1-Clinical course of patient.

Conversion: SI to traditional units-Urea $1 \mathrm{mmol} / 1 \approx 16 \mathrm{mg} / 100 \mathrm{ml}$.

\section{Comment}

Professor G P McNicol: Would Professor A G W Whitfield, who is to lead the discussion, like to indicate what other investigations would be helpful ?

Professor A G W Whitfield(4): I would be very surprised if the initial diagnosis was not that of meningococcal septicaemia. I would have done three blood cultures immediately, because the meningococcus grows poorly, and also a blood count. She clearly had a coccal septicaemia, and the haematologist might have seen Gram-negative diplococci within the leucocytes confirming its meningococcal nature. I would have been interested 